\title{
Properties of fatty acids in dispersions of emulsified lipid and bile salt and the significance of these properties in fat absorption in the pig and the sheep
}

\author{
BY C. P. FREEMAN \\ Unilever Research Laboratory, Colworth House, Sharnbrook, Bedford
}

(Received I Fuly $1968-$ Accepted 25 October 1968 )

\begin{abstract}
1. The behaviour of fatty acids in dilute bile salt solution and in dispersions of triglyceride in bile salt solution was examined. The properties of fatty acids in bile salt solution were defined in terms of their saturation ratio, and of the critical micellar concentration of bile salt for each fatty acid as solute. The partition of fatty acids between the oil phase and the micellar phase of the dispersions was defined as the distribution coefficient $K M / O$. The phases were separated by ultracentrifugation.

2. Of the fatty acids examined, palmitic and stearic acids behaved in bile salt solution as typical non-polar solutes. Lauric, oleic and linoleic acids had properties similar to typical amphiphiles. The effectiveness of these and other amphiphiles was expressed in terms of an amphiphilic index.

3. The trans-fatty acids, vaccenic acid and linolelaidic acid possessed solubility properties similar to their $c i s$-isomers. The properties of elaidic acid were intermediate between those of the non-polar and the amphiphilic solutes.

4. The distribution coefficients of fatty acids differed less significantly than their solubilities in bile salt solution, but were influenced to some extent by the composition of the oil phase.

5. The effect of $\mathrm{pH}$ on the partition of fatty acids was similar for all fatty acids examined. There was a marked increase in the partition of fatty acids in the micellar phase as $\mathrm{pH}$ increased above $6 \cdot 2$.

6. In the presence of $\mathrm{Ca}^{2+}$ ions above a threshold concentration of $\mathrm{x}$ m-equiv./l, and at a $\mathrm{pH}$ higher than 6.4 , the partition of stearic acid in the micellar phase of the bi-phasic system was restricted. No interaction of $\mathrm{Ca}^{2+}$ ion and $\mathrm{pH}$ was observed with oleic acid.

7. The effect of some amphiphiles on the distribution coefficient of stearic acid was examined. The capacity of lysolecithin to solubilize stearic acid in the micellar phase of dispersions was about twice that of $\mathrm{I}$-mono-olein. The significance of the results in relation to fat absorption in the pig and the sheep is discussed.
\end{abstract}

The physico-chemical state of lipid in the intestinal lumen during the digestion of fat is that of a micellar phase, containing mainly the products of lipolysis solubilized in bile salt solution, in continuous equilibrium with an emulsified oil phase (Hofmann \& Borgström, i 1962). Inter-species differences exist in the lipid composition of the two phases, as a result of variations in the extent of lipolysis characteristic of each species. The lipid composition of the micellar phase in the pig is similar to that in man (Freeman, Annison, Noakes \& Hill, 1967), being mainly fatty acid and monoglyceride. In the sheep, because of the extensive lipolysis and hydrogenation that occurs in the rumen (Bath \& Hill, 1967), the micellar lipid is predominantly in the form of free fatty acids, together with lysolecithin (Leat \& Harrison, 1967).

Fatty acids are the major components of the micellar phase of both species, and because of the significance of micellar lipid in the absorption of fat, are therefore important as the principal form in which lipid is absorbed. Further, the equilibrium between the oil and aqueous phases and the distribution of lipids between the two 
phases may be important as a site where a selective mechanism might exist which controls fatty acid absorption (Freeman et al. 1967).

Clearly, solubility is an important determinant in the distribution of a component between phases, and the solubility of monoglycerides in bile salt solution has been studied in some detail (Hofmann, I963a,b). The solubility characteristics of fatty acids are less well documented, although recently Borgström (1967) has described the partition of some lipids between emulsified oil and bile salt micellar phases in experiments using Millipore filters to separate the two phases.

The present work is part of a study on the absorption of fat in the pig and the sheep, with particular reference to the factors which influence the absorption of fatty acids, and is concerned with two aspects of fatty acid behaviour. Firstly the solubility of fatty acid in dilute bile salt solutions has been characterized in terms of critical micellar concentration (CMC) and saturation ratio (Hofmann, 1963a). Secondly, the partition of fatty acid between equilibrated oil and micellar phases has been studied with ultracentrifugation to separate the phases. The effect on the partition of fatty acids of amphiphilic materials and other factors has been examined in relation to their physiological significance.

\section{EXPERIMENTAL}

\section{Materials}

The cis-fatty acids and elaidic acid (trans-18:ı $\Delta 9$ ) were obtained from Sigma Chemical Company Ltd, London and were at least $99 \%$ pure. The trans-isomer of vaccenic acid (trans-I8: $\mathrm{x} \Delta \mathrm{I} \mathrm{I}$ ) was isolated from crude vaccenic acid (Koch-Light, Colnbrook, Bucks) by preparative thin-layer chromatography (TLC) of the methyl esters on chromatoplates of silica gel impregnated with silver nitrate employing triple-development in a diethyl ether-hexane $(5: 95, \mathrm{v} / \mathrm{v})$ system. Linolelaidic acid (trans-trans-18:2 $\Delta 9,12$ ) was obtained from Applied Science Laboratories, State College, Penn., USA. Lysolecithin was supplied by Koch-Light, Colnbrook, and was about $98 \%$ pure. Sucrose monopalmitate and sucrose dipalmitate were a gift from the Colonial Sugars Company, Gramercy, Louisiana, USA, and were about $90 \%$ pure.

Sodium glycodeoxycholate (NaGDC) was obtained from Maybridge Research Chemicals, Cornwall, and appeared to be about $95 \%$ pure when examined by thin-layer chromatography.

Tritiated and $\left[\mathrm{I}^{14} \mathrm{C}\right]$ fatty acids were obtained from the Radiochemical Centre, Amersham. $\left[\mathrm{I}^{14} \mathrm{C}\right]$ elaidic acid and $\left[\mathrm{I}^{14} \mathrm{C}\right]$ linolelaidic acid were prepared by isomerization of $\left[\mathrm{I}^{14} \mathrm{C}\right]$ oleic acid and $\left[\mathrm{I}^{14} \mathrm{C}\right]$ linoleic acid respectively in $6 \mathrm{M}-\mathrm{HNO}_{3}$, containing $2 \mathrm{M}-\mathrm{NaNO}_{2}$ for $\mathrm{I} \mathrm{h}$ at $65^{\circ}$. The isomers were separated by $\mathrm{AgNO}_{3}-\mathrm{TLC}$ as described above. ${ }^{14} \mathrm{C}$-labelled trans-vaccenic acid was prepared from the lipid extract of a culture of Rhodopseudomonas palustris grown on a $\left[{ }^{14} \mathrm{C}\right]$ acetate source, by isomerization and isolation of the products by $\mathrm{AgNO}_{3}-\mathrm{TLC} .{ }^{14} \mathrm{C}$-labelled lysolecithin was prepared from randomly labelled lecithin (isolated from a culture of Euglena gracilis inoculated with $\mathrm{NaH}^{14} \mathrm{CO}_{3}$ ) by incubation with phospholipase A (from 
Crotalus adamanteus; Koch-Light Laboratories Ltd, Colnbrook, Bucks) and isolation of the products by TLC.

Bile salt solutions of the required strength were prepared by diluting a $40 \mathrm{~mm}$ aqueous solution of sodium glycodeoxycholate ( $0.15 \mathrm{M}$ with respect to $\mathrm{Na}^{+}$ions) with phosphate buffer or, for the experiments in which $\mathrm{Ca}^{2+}$ ions were present, with sodium hydrogen malate buffer. Both buffers were prepared as described by Hofmann (1963a).

\section{Methods}

Radioactivity measurements. The radioactivity of micellar solutions was assayed by liquid scintillation counting (Packard Tri-Carb Liquid Scintillation Spectrometer), an external standard of ${ }^{226} \mathrm{Ra}$ being used to correct for quenching. The aqueous solutions ( $\mathrm{I} \mathrm{ml}$ ) were mixed with $\mathrm{I} 5 \mathrm{ml}$ of a mixture $(2: \mathrm{I}, \mathrm{v} / \mathrm{v})$ of toluene containing $0.4 \%$ 2,5-diphenyloxazole (PPO) and a non-ionic detergent (Triton X-Ioo; Lennig Chemical Co., Jarrow-on-Tyne, England) which gave a single-phase system suitable for counting.

Solubility measurements. Excess palmitic, stearic, elaidic and vaccenic acids in over-saturated solutions of the acids in bile salt were present as finely divided crystalline precipitates; the solubilities of the ${ }^{14} \mathrm{C}$-labelled acids were therefore determined by the method described by Hofmann $\left(\mathrm{r}_{9} 6_{3} b\right)$. After allowing the filtrate to stand for several days at $37^{\circ}$ for the micro-crystalline excess to settle, a portion ( $1 \mathrm{ml}$ ) of the supernatant fraction was carefully withdrawn and counted as described above.

Lauric, oleic, linoleic and linolelaidic acids behaved similarly to I-mono-olein in bile salt solution in that turbidity was induced when the saturation level was exceeded. It was established that the extinction due to turbidity was linearly related to the amount of solute in excess, over a small range of excess, and thus the turbidimetric method described by Hofmann ( $1963 a$ ) for the determination of the solubility of mono-olein was adopted for these acids.

Partition experiments. Labelled solute, in solution in light petroleum (b.p. $40^{\circ}-60^{\circ}$ ), was transferred to small screw-cap vials (about $7 \mathrm{ml}$ volume), and triolein (Io $\mathrm{mg}$; containing $0.1 \%$ butylated hydroxy toluene) together with any other component under investigation, was added and the solvent removed under a stream of nitrogen. A solution of $0.5 \% \mathrm{NaGDC}(40 \mathrm{mM})$ was added and the contents of the vial were swirled vigorously. The volume was then made up to $5 \mathrm{ml}$ with phosphate buffer, the vial gassed with nitrogen, and sealed. After equilibrating at $37^{\circ}$, the vials were agitated for $30 \mathrm{~min}$ on an end-to-end shaker enclosed in an incubator. The contents were centrifuged at $50000 \mathrm{rev} / \mathrm{min}\left(\mathrm{I}_{5} 0000 \mathrm{~g}\right.$ ) for I h at $37^{\circ}$ (longer periods were found unnecessary) and the clear infranatant fraction (about $2.5 \mathrm{ml}$ ) was then withdrawn through the side of the centrifuge tubes by disposable syringe. Portions ( $\mathrm{I} \mathrm{ml}$ ) of this solution were assayed for radioactivity as described above.

The distribution coefficient, $K M / O$, is given by the ratio $M /(T-M)$, where $M$ is the radioactivity of the solute in the micellar phase, and $T$ is the total radioactivity of the solute in the oil-bile salt dispersion. $(T-M)$ is thus the radioactivity associated with the solute in the oil phase, when the volume of the aqueous phase and the volume of the dispersion are assumed to be identical. 
RESULTS

\section{Solubility determinations}

Solubility characteristics of fatty acids in bile salt solutions at $37^{\circ}$. Solubility curves for lauric, palmitic, stearic, oleic and linoleic acids and for the trans-acids elaidic, vaccenic and linolelaidic were constructed from the saturation values of these acids at bile salt concentrations ranging from $\circ$ to $10 \mathrm{~mm}$, and at $\mathrm{pH} 6.3$. From these curves, the CMC of sodium glycodeoxycholate for each fatty acid as solute and the saturation ratio of each fatty acid were calculated. These values were compared with those for azobenzene and I-mono-olein in dilute bile salt solution which Hofmann (1963a) examined as representing typical non-polar and polar (amphiphilic) solutes respectively.

Table I. Critical micellar concentration and saturation ratio of fatty acids in sodium glycodeoxycholate solution at $37^{\circ}$

Palmitic acid
Stearic acid
Oleic acid
Linoleic acid
Lauric acid
Elaidic acid (trans-1 $8:$ I $\Delta 9)$
Vaccenic acid (trans-18:1 $\Delta \mathrm{I}$ I)
Linolelaidic acid $($ trans-trans-1 $8: 2 \Delta 9,12)$
Mono-olein*
Azobenzene*

$\begin{array}{cc}\text { CMC (mM) } & \begin{array}{c}\text { Saturation } \\ \text { ratio }\end{array} \\ 1.80 & 0.16 \\ 1.40 & 0.07 \\ 0.55 & 1.04 \\ 0.35 & 0.81 \\ 0.15 & 1.86 \\ 1.20 & 0.51 \\ 0.70 & 1.39 \\ 0.30 & 1.35 \\ 0.60 & 1.70 \\ 1.90 & 0.06\end{array}$

Palmitic and stearic acids behaved as typical non-polar solutes, i.e. the CMC's of $\mathrm{NaGDC}$ for these acids were high and their saturation ratios low, the values of both being similar to those of azobenzene (Table $\mathrm{I}$ ). The saturation ratio of palmitic acid was higher than that of stearic acid, probably because of its smaller molar volume. With oleic acid, on the other hand, the CMC was almost the same as that for I-monoolein, although its saturation ratio was not as high. Values for linoleic acid were similar to those for oleic acid; although more polar than oleic acid, its saturation ratio was lower. The CMC for lauric acid and its saturation ratio were particularly high compared with I-mono-olein.

Of the trans-acids, the CMC for elaidic acid was higher, and the saturation ratio lower than for its $c i s$-isomer oleic acid, the values being intermediate between those of the non-polar group of fatty acids and the amphiphilic solutes. On the other hand, with trans-vaccenic acid, which differs from elaidic acid only in the position of the double-bond, the saturation ratio was significantly higher than that of oleic acid.

Comparative effect of added amphiphiles on the solubility of stearic acid in bile salt solution. From the above results, lauric, oleic and linoleic acids would be expected to exhibit typical amphiphilic properties in bile salt solution, the most relevant of which in the physiological context is the ability to enhance the micellar solubilization of non-polar solutes. Since normally a mixture of both polar and non-polar fatty acids 
is present in the intestinal lumen, and the solubility of palmitic and stearic acids is limiting, it was of interest to examine the interaction of the latter with polar (amphiphilic) fatty acids and other amphiphiles.

The effect of the concentration of several amphiphiles on the solubilization of $\left[\mathrm{I}-{ }^{14} \mathrm{C}\right]$ stearic acid in $4 \mathrm{~mm}-\mathrm{NaGDC}$ solution at $37^{\circ}$ is shown graphically in Fig. I. Over a limited range, sucrose dipalmitate (SDP) was the most effective of the amphiphiles examined in increasing the solubilization of the non-polar solute.

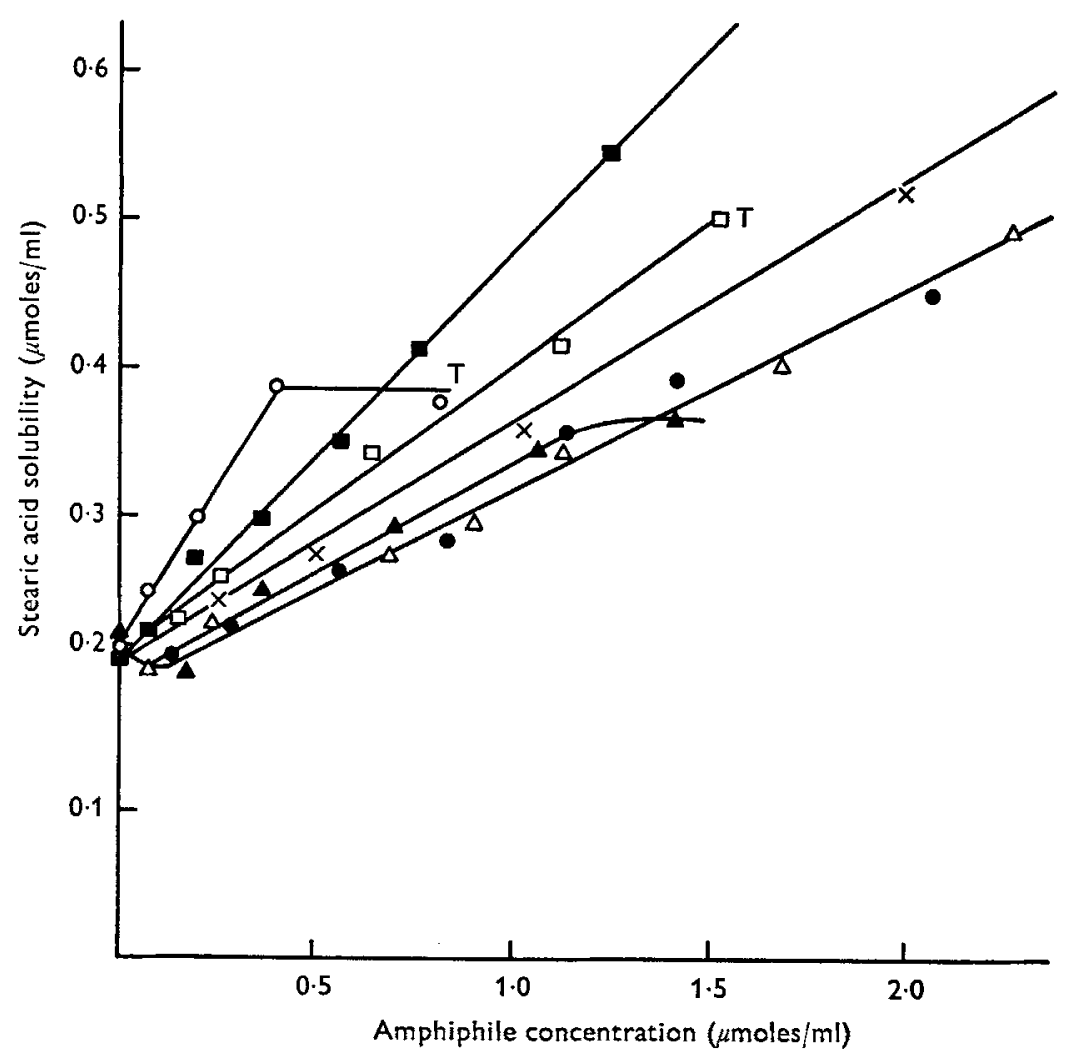

Fig. I. Effect of added amphiphile on the solubilization of stearic acid in $4 \mathrm{mM}-\mathrm{NaGDC}$ $\left(\mathrm{pH} 6.3\right.$ ) at $37^{\circ}$. O, oleic acid; $O$, sucrose dipalmitate; $\triangle$, I-mono-olein; $\boldsymbol{\Delta}$, linoleic acid; $\square$, sucrose monopalmitate; $\boldsymbol{\square}$, lysolecithin; $\times$, lauric acid. T denotes appearance of turbidity.

Increasing the level of SDP above $0.4 \mu$ moles $/ \mathrm{ml}$ effected no further increase in the solubilization of stearic acid, and at $0.8 \mu \mathrm{moles} / \mathrm{ml}$ turbidity was induced. At the latter point the saturation level of SDP in bile salt solution is exceeded. Sucrose monopalmitate was less effective than the di-ester, but had a higher solubility in NaGDC solution. Over a wide range of added amphiphile, lysolecithin caused a greater increase in stearic acid solubility, mole for mole, than any of the amphiphiles examined. It was interesting to note that the effect of oleic acid on stearic acid solubility was identical to that of mono-olein. 
The effectiveness of amphiphiles in enhancing the solubility of stearic acid in bile salt solution can be summarized in terms of an 'amphiphilic index' defined as

$$
\frac{\text { increase in stearic acid solubility (in } \mu \text { moles) }}{\text { amount of added amphiphile (in } \mu \text { moles) }}
$$

at a constant bile salt concentration, and is given by the slope of the linear portion of the curves shown in Fig. I. The values are presented in Table 2.

\section{Table 2. Amphiphilic indices of some polar solutes}

$\left.\begin{array}{lc}\text { Amphiphile } & \left.\begin{array}{c}\text { Amphiphilic index } \\ \text { increase in stearic acid solubility }(\mu \text { moles })\end{array}\right) \\ \text { Oleic acid } & 0.138 \\ \text { I-Monount of added amphiphile }(\mu \text { moles })\end{array}\right)$

Table 3. Relative rate of incorporation of $\left[{ }^{3} \mathrm{H}\right]$ stearic acid and $\left[\mathrm{r}-{ }^{14} \mathrm{C}\right]$ oleic acid into the micellar phase of an ail-bile salt dispersion

\begin{tabular}{|c|c|c|}
\hline \multirow{2}{*}{$\begin{array}{l}\text { Time after } \\
\text { dispersing } \\
\text { (h) }\end{array}$} & \multicolumn{2}{|c|}{${ }^{3} \mathrm{H}$ to ${ }^{14} \mathrm{C}$ ratio in micellar phase } \\
\hline & - I-Mono-olein & + I-Mono-olein \\
\hline 0 & $10 \cdot 6$ & 10.0 \\
\hline I. 5 & $9 \cdot 9$ & $9 \cdot 8$ \\
\hline $3 \cdot 0$ & - & II $\cdot 6$ \\
\hline $6 \cdot 0$ & 10.7 & $10 \cdot 3$ \\
\hline $9 \cdot 0$ & $9 \cdot 5$ & I I*4 \\
\hline $24 \cdot 0$ & 10.0 & $11 \cdot 7$ \\
\hline $48 \cdot 0$ & $10 \cdot 0$ & I I 3 \\
\hline 120.0 & II $\cdot 0$ & I I'3 \\
\hline
\end{tabular}

The dispersion consisted of triolein (ro $\mathrm{mg}$ ), $\left[{ }^{3} \mathrm{H}\right] \mathrm{stearic}$ acid $(0 \cdot 2 \mathrm{mg}),\left[\mathrm{I}-{ }^{14} \mathrm{C}\right]$ oleic acid $(0 \cdot 2 \mathrm{mg})$ in $4 \mathrm{~mm}-\mathrm{NaGDC}$ solution $(5 \mathrm{ml})$ at $37^{\circ}$. Where indicated, $\mathrm{I}$-mono-olein $(\mathrm{I} \mathrm{mg})$ was added to the dispersion.

\section{Partition experiments}

Relative rate of solubilization of stearic and oleic acids in the micellar phase of an oil-bile salt dispersion. $\left[{ }^{3} \mathrm{H}\right]$ Stearic acid $(0.2 \mathrm{mg} ; 35 \mathrm{~m} \mu \mathrm{c})$ and $\left[\mathrm{I}^{14} \mathrm{C}\right]$ oleic acid $(0.2 \mathrm{mg}$; $4 \mathrm{~m} \mu \mathrm{c}$ ), after rapid mixing, were equilibrated at $37^{\circ}$ in a triolein-bile salt dispersion as described above, for periods ranging from $I h$ to 5 days, in the presence or absence of I-mono-olein ( $\mathrm{I} \mathrm{mg).}$

It was clear (Table 3 ) that equilibration of both fatty acids in the two-phase system was rapid; equilibration was achieved at least within the first hour after introduction to the system (it was not possible to examine intervals of less than $I \mathrm{~h}$ because of the time required for centrifugation). The relative rates of entry of these fatty acids into the micellar phase of the disperse system contrast with their rates of 
solubilization in a single-phase bile salt solution, where solubilization is achieved rapidly with oleic acid but may take several days with stearic acid.

The presence of mono-olein had no effect on the rate of equilibration of either acid but it did affect the distribution coefficient of stearic acid in favour of the micellar phase.

Distribution coefficients of fatty acids of different chain length. The distribution coefficients of some fatty acids, and of mono-olein, are presented in Table 4 . The effect of the addition of I mono-olein ( $\mathrm{mg}$ ) or oleic acid $(2 \mathrm{mg}$ ) to the system was also examined. Fatty acids of chain length less than twelve carbon atoms were not examined, since they have a definite solubility in water and hence their distribution is not strictly analogous to partition by micellar solubilization.

Table 4. Distribution coefficients (K M/O) of fatty acids of different chain length at $\mathrm{pH} 6 \cdot 3$, and effect of $\mathrm{I}-\mathrm{mono}$-olein and oleic acid

\begin{tabular}{|c|c|c|c|}
\hline \multirow[b]{2}{*}{ Fatty acid } & \multirow[b]{2}{*}{$K M / O$} & \multicolumn{2}{|c|}{$K M / O$} \\
\hline & & $+\mathrm{I}$-Mono-olein & + Oleic acid \\
\hline Lauric & $I \cdot 70$ & $2 \cdot 5 \mathrm{I}$ & $1 \cdot 02$ \\
\hline Myristic & $1 \cdot 12$ & - & - \\
\hline Palmitic & 0.88 & I.02 & 0.46 \\
\hline Stearic & 0.90 & - & - \\
\hline Oleic & 0.77 & I.04 & 0.68 \\
\hline Elaidic & 0.87 & - & - \\
\hline trans-vaccenic & 0.89 & - & - \\
\hline Linoleic & 0.93 & I'I 8 & 0.60 \\
\hline Linolelaidic & $r \cdot 08$ & - & - \\
\hline I-Mono-olein & $5 \cdot 05$ & $4 \cdot 76$ & $4 \cdot 74$ \\
\hline
\end{tabular}

Disperse system: triolein (Io $\mathrm{mg}$ ) in $4 \mathrm{~mm}-\mathrm{NaGDC}$ solution $(5 \mathrm{ml}$ ) to which was added the fatty acid ( $0.2 \mathrm{mg})$ and where indicated $\mathrm{I}$-mono-olein $(\mathrm{I} \mathrm{mg})$ or oleic acid $(2 \mathrm{mg})$.

Table 5. Effect of the triglyceride composition of the oil phase on $\mathrm{K} \mathrm{M} / \mathrm{O}$ of palmitic and oleic acid at $\mathrm{pH} 6 \cdot 3$

\begin{tabular}{lccc}
\multicolumn{1}{c}{ Oil phase } & $\begin{array}{c}c . \mathrm{C}_{16: 0} \\
\text { content } \\
(\%)\end{array}$ & $\overbrace{\text { Palmitic acid }}^{K M / O}$ & Oleic acid \\
Triolein (O-O-O) & $\circ$ & 0.91 & 0.70 \\
Soya-bean oil TG & 10 & 0.92 & 0.76 \\
Lard TG & 25 & 0.83 & 0.77 \\
Di-oleyl palmitin (P-O-O) & 33 & 0.84 & 0.67 \\
Palm oil & $40 \cdot 0$ & 0.75 & 0.68
\end{tabular}

Disperse system: oil phase ( $10 \mathrm{mg})+$ palmitic $(0.2 \mathrm{mg})$ or oleic acid $(0.2 \mathrm{mg})$ in $4 \mathrm{mM}-\mathrm{NaGDC}$ solution $(5 \mathrm{ml})$. TG, triglycerides.

Two features of these results were particularly notable, firstly that palmitic and stearic acids had a greater partition in favour of the micellar phase than did oleic acid (cf. the solubility measurements), and secondly that oleic acid consistently depressed the partition ratio of other fatty acids.

It was considered that the low distribution coefficient of oleic acid relative to that of palmitic or stearic acid was associated with the unrepresentative nature of the oil 
phase, triolein. The effect of the triglyceride composition of the oil phase on the distribution of palmitic and oleic acid was examined. Oil phases of synthetic triglycerides $(\mathrm{O}-\mathrm{O}-\mathrm{O}$ and $\mathrm{P}-\mathrm{O}-\mathrm{O})$ and of the triglycerides of natural fats were used. It was evident from the results (Table 5) that the higher distribution coefficient of palmitic acid relative to oleic acid observed above was not an isolated phenomenon associated with the unrepresentative nature of the oil phase, since with each of the

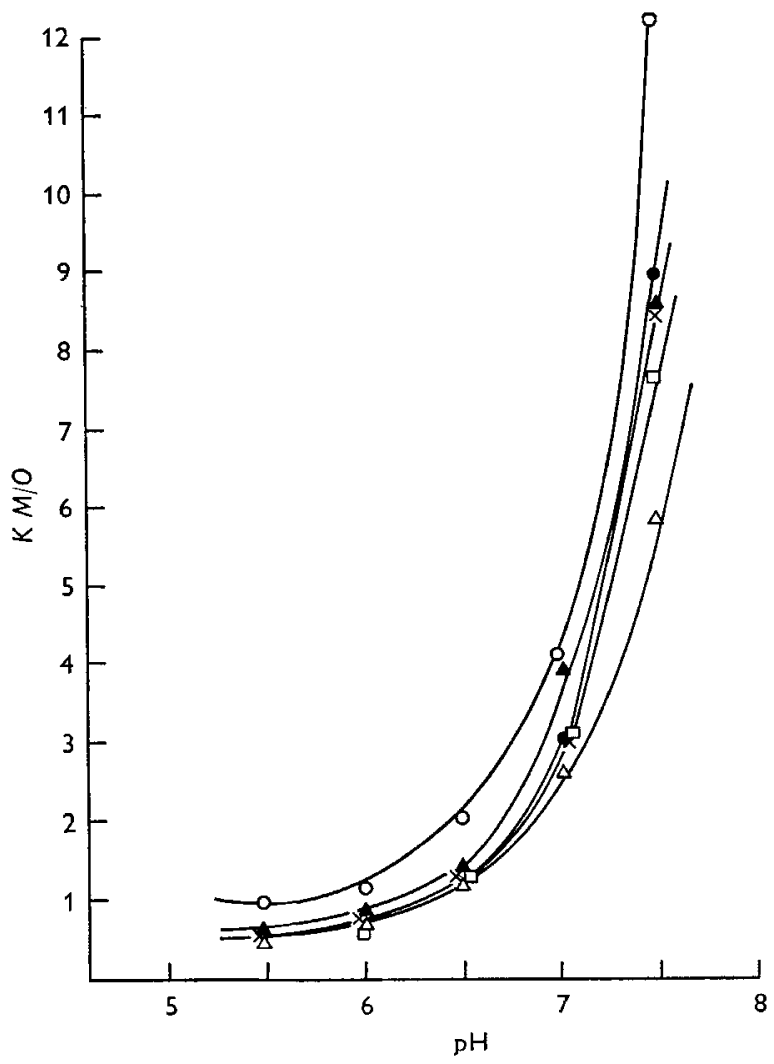

Fig. 2. Effect of $\mathrm{pH}$ on the distribution coefficient $(K M / O)$ of different fatty acids. Dispersions consisted of triolein ( $10 \mathrm{mg}$ ) and fatty acid $(0.2 \mathrm{mg})$ in $4 \mathrm{~mm}-\mathrm{NaGDC}(5 \mathrm{ml})$ at $37^{\circ}$. O, lauric acid; $\bullet$, linoleic acid; $\Delta$, palmitic acid; $\Delta$, myristic acid; $\square$, oleic acid; $x$, stearic acid.

oil phases examined $K M / O$ of palmitic acid exceeded that of oleic acid. When examined in relation to the palmitic acid content of the triglycerides, the results suggest that the affinity of palmitic acid for the oil phase increased with the palmitic acid content of the oil phase. This undoubtedly represents some oversimplification, since the effect of other fatty acids in the natural triglycerides and the distribution of triglyceride species within each fat may influence fatty acid partition. The effect of triglyceride composition on the distribution of oleic acid between the two phases was less marked.

The effect of oleic acid, and other amphiphiles, on the distribution coefficient of fatty acids was examined in more detail. 
Effect of $p H$ on $\mathrm{K} \mathrm{M} / \mathrm{O}$ of fatty acids of different chain length. The relationship between the distribution coefficient of fatty acids of I2- to I8-carbon chain length, and $\mathrm{pH}$ is shown in Fig. 2. Each of the fatty acids examined showed a similar relationship between $\mathrm{pH}$ and $K M / O$; in the lower $\mathrm{pH}$ range (up to 6) $K M / O$ values were low and changed little with $\mathrm{pH}$, but between $\mathrm{pH} 6.5$ and 7.5 a very marked increase in the affinity of fatty acids for the micellar phase was observed. Over a comparable $\mathrm{pH}$ range, the shape of the curve closely resembled that described for oleic acid by Borgström (1967), who has suggested that the curve represents the dissociation curve for the acid under these conditions.

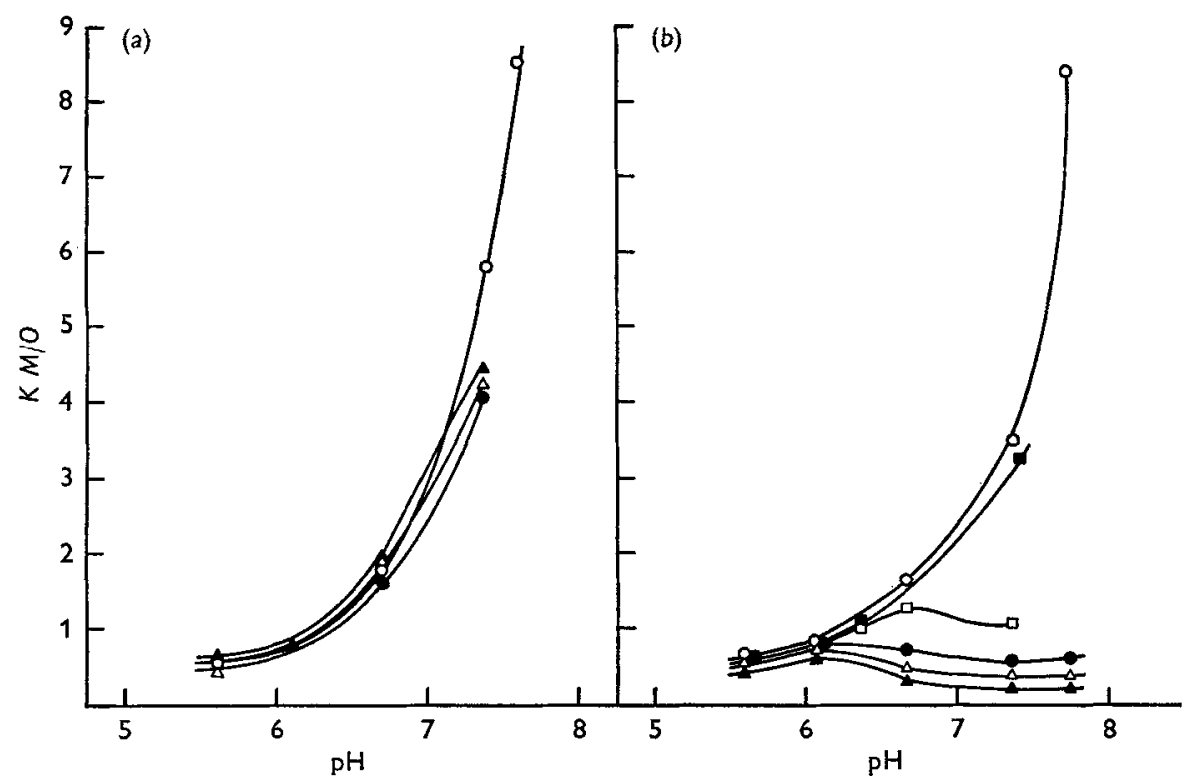

Fig. 3. Effect of $\mathrm{pH}$ and $\mathrm{Ca}^{2+}$ ion concentration on $K M / O$ of $(a)$ oleic acid and $(b)$ stearic acid. Disperse system: triolein (10 $\mathrm{mg}$ ), oleic or stearic acid $(0.2 \mathrm{mg})$ in $4 \mathrm{mM}-\mathrm{NaGDC}(5 \mathrm{ml})$ at $37^{\circ} . \mathrm{Ca}^{2+}$ ion concentrations denoted by: 0 , no $\mathrm{Ca}^{2+} ; 0,5 ; \triangle, 10 ; \Delta, 20$ and in addition (b) $\mathbf{\square}, 0.2 ; \square$, I m-equiv./1.

The interaction of $\mathrm{pH}$ and $\mathrm{Ca}^{2+}$ ions with the partition of oleic acid and stearic acid. The effect of the presence of $\mathrm{Ca}^{2+}$ ions at three different levels (5, 10 and $20 \mathrm{~m}$-equiv./1.) on the distribution coefficients of stearic and oleic acids over the $\mathrm{pH}$ range $5.0-7.5$ was examined. The presence of $\mathrm{Ca}^{2+}$ ion at any of the levels examined had no significant effect on the partition of oleic acid over almost the entire $\mathrm{pH}$ range (Fig. $3 a$ ), but did lower $K M / O$ slightly at $\mathrm{pH} 7.5$. In contrast, 5 , Io or $20 \mathrm{~m}$-equiv. $\mathrm{Ca}^{2+} / 1$. caused a drop in the partition of stearic acid at $\mathrm{pH} 6.4$ (Fig. 3 b). No further increase in the distribution of stearic acid in the micellar phase was observed as the $\mathrm{pH}$ was increased beyond 6.4, whereas in the absence of $\mathrm{Ca}^{2+} K M / O$ rose markedly, as expected from previous experiments. Two further levels of $\mathrm{Ca}^{2+}(0 \cdot 2$ and I m-equiv./1.) were examined in order to determine the threshold $\mathrm{Ca}^{2+}$ ion concentration at which the effect occurred. It was established that for stearic acid in an oil-bile salt dispersion 
there was a critical $\mathrm{pH}$ at about $6 \cdot 4$ and a threshold $\mathrm{Ca}^{2+}$ ion level of $\mathrm{r} \cdot 0$ m-equiv./1. beyond which no further increase in its partition in the micellar phase occurred. It is unlikely that the $\mathrm{Ca}^{2+}$ interaction is with the conjugated bile salts, since the calcium salts of the latter are apparently sufficiently soluble to form micellar aggregates (Hofmann, $196_{3} a$ ). The specific nature of the effect is undoubtedly due to the lower solubility of the calcium salt of stearic acid compared with calcium oleate. The salts

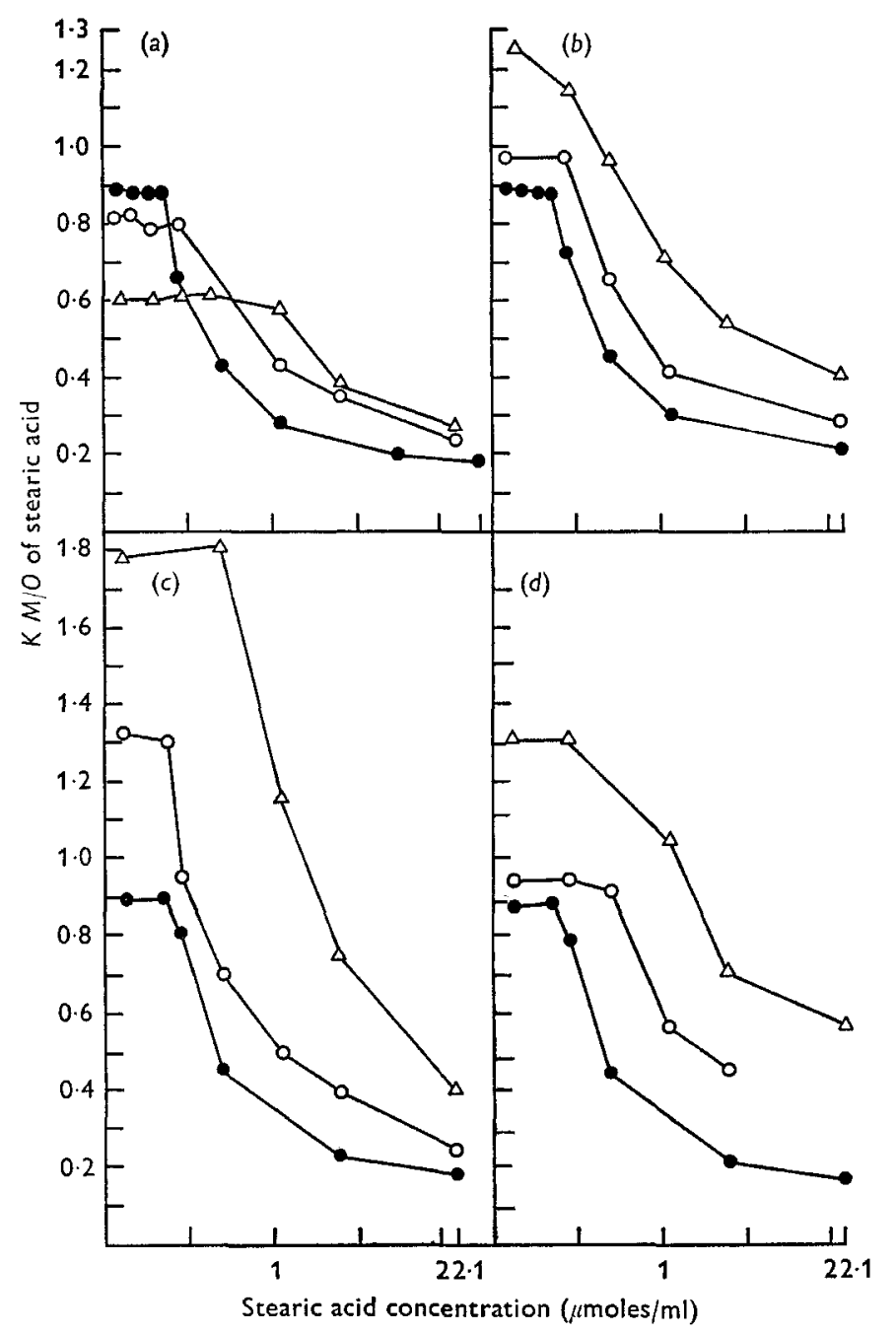

Fig. 4. Effect of added amphiphiles and concentration of stearic acid on $K M / O$ of stearic acid. Amphiphiles were (a) oleic acid, (b) I-mono-olein, (c) lysolecithin and (d) sucrose monopalmitate; $\bullet$, no amphiphile; $O$, I $\mathrm{mg}$ amphiphile; $\triangle, 3 \mathrm{mg}$ amphiphile in dispersions of triolein ( $10 \mathrm{mg}$ ) and stearic acid in $4 \mathrm{mM}-\mathrm{NaGDC}(5 \mathrm{ml})$ at $37^{\circ}$.

would be formed only when the $\mathrm{pKa}$ of the fatty acid is attained or exceeded, and would indicate a $\mathrm{pKa}$ of approximately 6.5 for stearic acid under the conditions of these experiments. 
Effect of concentration of non-polar solute, and the interaction of added amphiphile, on $\mathrm{K} \mathrm{M} / \mathrm{O}$ of the solute. The effect of the concentration of $\left[\mathrm{I}^{14} \mathrm{C}\right]$ stearic acid on its distribution coefficient, and the interaction of two levels of the amphiphilic lipids oleic acid, I-mono-olein, lysolecithin and sucrose monopalmitate added to the system is shown graphically in Fig. 4.

In the absence of amphiphile, on increasing the concentration of stearic acid in the system, the distribution coefficient of stearic acid remained constant until a level of $0.39 \mu \mathrm{moles} / \mathrm{ml}$ was attained, when a steep fall in $K M / O$ was observed. This point represents saturation of the micellar phase with stearic acid. At a $K M / O$ value of 0.9 , this point would correspond to a saturation level of $0.17 \mu$ moles $/ \mathrm{ml}$ of stearic acid in the micellar phase of the bi-phasic system, and is in good agreement with the value determined by solubility measurement in $4 \mathrm{~mm}-\mathrm{NaGDC}$ solution. Over the range of stearic acid concentrations examined, no crystalline excess was visible in the aqueous phase, nor was any change in the radioactivity of the micellar phase observed when the separated micellar solution was allowed to stand for I-2 days to allow sedimentation of any micro-crystalline excess. Excess stearic acid was thus completely retained in the oil phase.

The effect of the addition of oleic acid ( $\mathrm{mg}$ ) to the system was twofold. At stearic acid levels below the saturation point oleic acid depressed $K M / O$ of stearic acid (Fig. 4a). Secondly, the presence of oleic acid extended the point at which stearic acid saturated the micellar phase (this accords with the effect of oleic acid on the solubilization of stearic acid established in the solubility experiments). Further addition of oleic acid to the system enhanced both effects, i.e. caused a further depression of $K M / O$ of stearic acid below its saturation point, and a further extension of the point at which saturation occurred.

Unlike oleic acid, I-mono-olein elevated the distribution coefficient of stearic acid, and had an effect similar to that of oleic acid in increasing the level of stearic acid capable of being solubilized in the micellar phase without oversaturation (Fig. $4 b$ ).

Lysolecithin had a similar, but far more pronounced, effect upon the distribution of stearic acid than did I-mono-olein (Fig. $4 c$ ).

If the graphs are considered as phase diagrams, with the curve corresponding to the boundary between oil and micellar phases, the area below each curve gives a comparative measure of the amount of stearic acid solubilized in the micellar phase of the dispersion. It can be clearly seen that because of its pronounced effect in elevating the distribution coefficient of stearic acid and in extending the saturation point, the over-all effect of lysolecithin on the distribution of stearic acid is significantly greater than that of either I-mono-olein or oleic acid. Over comparable concentration ranges, the effectiveness of lysolecithin, sucrose monopalmitate, I-mono-olein or oleic acid (all at the $3 \mathrm{mg}$ level) on the capacity of the micellar phase of the dispersion to solubilize stearic acid is of the order $2 \cdot 6, \mathrm{I} \cdot 9, \mathrm{I} \cdot 5, \mathrm{r} \cdot 2$ respectively, calculated from the area under the appropriate curves, relative to a value of $\mathrm{I}$ for stearic acid alone.

Similar profiles could be predicted for other amphiphiles from a knowledge of their amphiphilic index and their effect on $K M / O$ of stearic acid. Lauric acid and 
linoleic acid when examined for their effect on the distribution coefficient of stearic acid gave values not significantly different from that of stearic acid.

Amphiphilic interaction and its effect on $\mathrm{K} \mathrm{M} / \mathrm{O}$ of stearic acid. Competition between polar solutes for micellar space in monophasic bile salt solutions has been reported (Hofmann \& Borgström, I962), and it was therefore interesting to examine the possibility of competition in the disperse system and its effect on the distribution of a non-polar solute. In this experiment $\left[{ }^{3} \mathrm{H}\right]$ stearic acid $(0.4 \mathrm{mg})$ at a level approaching its saturation point was distributed in the disperse system containing $\left[\mathrm{I}^{14} \mathrm{C}\right]$ lysolecithin $(2 \mathrm{mg})$. Increasing amounts of $\mathrm{I}$-mono-olein (up to $4 \mathrm{mg}$ ) were added to the system, and its effect on the labelled components was examined. It is clear (Table 6) that no displacement of one amphiphile in favour of another occurred, since the level of lysolecithin in the micellar phase remained unchanged throughout the additions of mono-olein. Mono-olein continued to increase $K M / O$ of stearic acid with each addition to the system.

Similar results were obtained when $\mathrm{I}$-mono-olein was added to a stearic acid-oleic acid disperse system; increasing amounts of mono-olein, as well as increasing $K M / O$ of stearic acid, increased the micellar concentration of oleic acid concomitantly.

Table 6. Interaction of $\mathrm{I}-$ mono-olein and lysolecithin on $\mathrm{K} \mathrm{M} / \mathrm{O}$ of stearic acid

$\begin{gathered}\text { r-Mono-olein } \\ \text { added } \\ \text { (mg) }\end{gathered}$
0
0.25
0.50
1.00
2.00
3.00
4.00

$K M / O$
of stearic
acid
$I \cdot 60$
$I \cdot 45$
$I \cdot 55$
$I \cdot 79$
$I \cdot 80$
$2 \cdot 26$
$2 \cdot 40$

Activity of
lysolecithin in
micellar phase
$(\mathrm{m} \mu \mathrm{c})$
$2 \cdot 86$
$2 \cdot 86$
$2 \cdot 83$
$2 \cdot 94$
$2 \cdot 81$
$2 \cdot 91$
$2 \cdot 79$

Disperse system: triolein (10 mg) $+\left[{ }^{2} \mathrm{H}\right]$ stearic acid $(0.4 \mathrm{mg})+\left[\mathrm{I}^{14} \mathrm{C}\right]$ lysolecithin $(2 \mathrm{mg})$ in $4 \mathrm{~mm}-$ NaGDC solution $(5 \mathrm{ml})$ to which was added $\mathrm{I}-$ mono-olein as indicated.

\section{DISCUSSION}

The over-all process of intestinal lipid absorption involves a sequence of interdependent events in continuous equilibrium with each other, and at each one of which fatty acid specificity may occur resulting in selectivity in its absorption. In the pig, the uptake by the small intestine of fatty acids from a mixed micellar solution has been shown to be non-specific (Freeman et al. 1967; Freeman, Noakes, Annison $\&$ Hill, r968), but once penetration of the mucosal cell is achieved marked specificity is observed in the rate at which fatty acids are incorporated into mucosal triglycerides. However, this step is apparently not rate-limiting since it does not influence the rate at which fatty acids are removed from the lumen. Although transport of triglycerides out of the cell as chylomicrons may limit the rate of fat absorption over-all, it is unlikely to be fatty acid specific. Thus the luminal oil phase-bile salt solution equilibrium, and in particular the rate and extent of formation of mixed micelles in the system by fatty acids, is important in controlling the absorption of fatty acids. 
The results suggest that when fatty acids are released into oil-bile salt dispersions the rate at which they establish equilibrium between the two phases is rapid and apparently non-specific. Much significance consequently attaches to the extent to which fatty acids of different chain-length and degree of unsaturation can be solubilized in the micellar phase of similar dispersions. The capacity of the micellar phase of an oil-bile salt dispersion to solubilize fatty acids is clearly a function of two parametersthe solubility of the fatty acid in dilute bile salt solution, and its partition between the two phases. The distribution coefficients of fatty acids differed little, though influenced to some extent by the composition of the oil phase, compared with the marked differences in their solubility properties in bile salt solutions. Palmitic and stearic acid behave as typical non-polar solutes, and the low saturation ratios of these acids and the high bile salt CMC associated with them are patently two factors which limit their absorption.

Several factors of physiological significance were clearly capable of influencing micellar capacity, either by their effect on the solubility of fatty acids or on their distribution coefficient or both. Thus the influence of $\mathrm{pH}$ on the distribution of fatty acids was similar for acids of different chain length or degree of unsaturation. At low $\mathrm{pH}$, that is below 6.0 when the fatty acids are undissociated, the distribution of fatty acids in favour of the micellar phase is limited. Under normal conditions, in the monogastric animal the $\mathrm{pH}$ of the small intestine is higher than this value, ranging from $5 \cdot 7-6 \cdot 0$ in the duodenal region to $6 \cdot 2-6 \cdot 4$ in the jejunal-ileal region. In exceptional circumstances intestinal $\mathrm{pH}$ may fall below this range and impairment of fatty acid absorption as a result of reduced micellar solubilization would be expected. This may be the mechanism responsible for the defective fat absorption observed in rats when dilute solutions of lactic acid are infused into the upper small intestine (Hamilton, 1967).

The interaction of $\mathrm{Ca}^{2+}$ ion and $\mathrm{pH}$ on the distribution coefficient of fatty acids has important physiological implications, since in the presence of $\mathrm{Ca}^{2+}$ ions above a concentration of $\mathrm{I}$ m-equiv./1. and above $\mathrm{pH} 6 \cdot 4$, the distribution of stearic acid in the micellar phase is restricted. There is little information on the concentration of $\mathrm{Ca}^{2+}$ ion in intestinal contents, but from a small number of observations made in this laboratory on sheep and pigs receiving standard diets containing $3 \mathrm{~g}$ (sheep) and $8 \mathrm{~g}$ (pig) calcium per $\mathrm{kg}$, the $\mathrm{Ca}^{2+}$ ion concentration (20-40 m-equiv./l.) in the intestinal content appears to be well above the threshold value. However, $\mathrm{pH}$ levels in the duodenum of the sheep were much lower (about $\mathrm{pH} 2.5$ ) than in the pig, which would suggest that interaction of $\mathrm{Ca}^{2+}$ with stearic acid is less pronounced in the sheep than in the pig.

The properties of trans-fatty acids have particular significance in the ruminant where trans-isomers are produced as a result of the biohydrogenation of unsaturated fatty acids in the rumen, and are of interest in the non-ruminant in instances when hydrogenated fats form part of the diet. The evidence from the trans-acids examined suggests that the solubility and partition characteristics of the trans-isomers most likely to occur in the digestive tract should not present a barrier to their efficient absorption. Although the solubility of elaidic acid in bile salt solution was less than 
its cis-isomer, its properties did not place it in the same restricted category as palmitic and stearic acids.

Apart from the solubility of fatty acids per se, the most important factor which influences the micellar capacity of fatty acids such as palmitic and stearic acid is the type of amphiphile present in the dispersion. Amphiphiles present in the intestinal lumen may be of endogenous origin, derived from the breakdown of dietary fat (e.g. monoglycerides, polar fatty acids), or of extraneous origin (i.e. dietary additives). In this respect a difference exists between the sheep and the pig. In the latter, amphiphile is derived mainly from dietary fat in the form of monoglycerides and polar fatty acids. Lysolecithin on the other hand has an apparently minor role in micelle formation in the pig, since quantitatively the phospholipid fraction forms only a small part of the lipid in the micellar phase of intestinal contents (Freeman et al. 1967). By contrast, in the sheep there is an almost complete absence of amphiphilic monoglycerides or unsaturated fatty acids arriving in the small intestine. The lipid passing along the tract is composed mainly of unesterified saturated fatty acids and phospholipid (Bath \& Hill, 1967), and of the latter Leat \& Harrison (r967) have shown that $60-85 \%$ is accounted for by lysolecithin, apparently derived in situ from the action of phospholipase secreted in pancreatic juice on biliary lecithin (Leat, 1965). It has been suggested that in the ruminant lysolecithin replaces the function of monoglyceride in micelle formation in the monogastric animal. The efficient absorption of long-chain saturated fatty acids which occurs in the sheep (Andrews, 1966) indicates that there is an adequate supply of a highly effective amphiphile. The evidence of the present work demonstrates that not only is lysolecithin very effective in increasing the solubilization of long-chain saturated fatty acids (cf. the amphiphilic index of mono-olein and lysolecithin) but that it has a marked effect upon the distribution coefficients of non-polar solutes in dispersions. The net effect is a total capacity to solubilize stearic acid in the micellar phase of a bi-phasic system that is about twice that of I-mono-olein. Moreover, even at the relatively low level of lysolecithin used in the present experiments, an almost threefold increase in the amount of stearic acid solubilized in the micellar phase was achieved. Certainly the effectiveness of lysolecithin to enhance the solubilization of palmitic and stearic acids would outweigh that of linoleic or other unsaturated fatty acids released, concomitantly with lysolecithin, from lecithin in the small intestine, although the evidence indicates that the presence of unsaturated fatty acids would have an additive rather than competitive effect with lysolecithin.

The dependence of the non-ruminant upon a dietary supply of amphiphile provides an opportunity, where the level of natural amphiphile is deficient, to enhance the micellar solubilization, and hence the generally limited absorption of palmitic and stearic acids by dietary means. Synergism of this type has been reported in the chick, where it was observed that oleic acid was effective in increasing the absorption of free palmitic and stearic acids, but linoleic acid was reported to be less effective (Young \& Garrett, 1963). Although in the present work oleic acid was shown to be as effective as I-mono-olein in increasing the solubilization of stearic acid, its behaviour in dispersions tended to reduce its over-all effectiveness. On the other hand, the 
properties of linoleic acid both in the monophasic and disperse systems suggest that its synergistic effect would be quantitatively similar to that of oleic acid.

\section{REFERENCES}

Andrews, R. J. ( 1966 ). The utilization of dietary fat by ruminants. PhD Thesis, University of Nottingham.

Bath, I. H. \& Hill, K. J. (1967). F. agric. Sci., Camb. 68, I39.

Borgström, B. (1 967$)$. F. Lipid Res. 8, 598.

Freeman, C. P., Annison, E. F., Noakes, D. E. \& Hill, K. J. (1967). Proc. Nutr. Soc. 26, vii.

Freeman, C. P., Noakes, D. E., Annison, E. F. \& Hill, K. J. (1968). Br. F. Nutr. 22, 739.

Hamilton, J. R. (1967). Pediat. Res. I, 34I.

Hofmann, A. F. (1963a). Biochem. F. 89, 57.

Hofmann, A. F. ( 1963 b). Biochim. biophys. Acta 70, 306.

Hofmann, A. F. \& Borgström, B. (1962). Fedn Proc. Fedn Am. Socs exp. Biol. 21, 43.

Leat, W. M. F. (1965). Biochem. F. 94, 21 P.

Leat, W. M. F. \& Harrison, F. A. (1967). Biochem. F. 105, I3 P.

Young, R. J. \& Garrett, R. L. (1963). F. Nutr. 81, 32 I. 